(C) 2019 Metaphilosophy LLC and John Wiley \& Sons Ltd METAPHILOSOPHY

Vol. 50, No. 5, October 2019

0026-1068

\title{
RETHINKING EPISTEMIC RELATIVISM
}

\author{
NATALIE ALANA ASHTON
}

\begin{abstract}
Relativism" is often treated as a dirty word in philosophy, but relativistic theories are not entirely unappealing - they have features that might be tempting if they weren't thought to be outweighed by problematic consequences. The aim of this paper is to rethink both our attitude to epistemic relativism and the basic features of the view itself. The paper discusses four objections and uses them to isolate five constraints on a more plausible epistemic relativism. It then sketches out a view that meets all of these constraints. This stratified epistemic relativism offers a complex, socially informed picture of justification that accounts for the many different kinds of roles that epistemic agents act, and think, in accordance with each day, and can serve as a starting point for constructing a more detailed epistemic relativism, which could secure its appealing benefits without incurring the costs traditionally associated with relativist views.
\end{abstract}

Keywords: epistemic relativism, epistemic justification, social roles, equal validity, hinge epistemology.

\section{Introduction}

"Relativism" is often treated as a dirty word in philosophy. Showing that a view entails relativism is almost always considered tantamount to showing that it is unacceptable. But relativistic theories are not entirely unappealing - they have features that might be tempting if they weren't thought to be outweighed by problematic consequences. My aim in this paper is to rethink both our attitude to epistemic relativism and the basic features of the view itself. If we didn't already dismiss relativism as unsalvageable, and were open to attempting to secure its benefits, which considerations would be most important, and what changes would need to be made? What would a functioning version of epistemic relativism look like?

I begin by explaining the general features of relativism, specifically epistemic relativisms, before suggesting some benefits that a view of this kind could offer. I then explain the general formula that objections to epistemic relativism have taken and categorise four kinds of response. I discuss four objections in total, and in discussing each one I isolate the features that an epistemic relativism would need to incorporate in order to avoid the relevant objection. Finally, I summarise these features and sketch out a view I think has all of them. This view, which I call stratified epistemic 
relativism, offers a complex, socially informed picture of justification that accounts for the many different kinds of roles that epistemic agents actand think - in accordance with each day. I think this picture could serve as a starting point for constructing a more detailed epistemic relativism, which would be able to secure the appealing benefits I suggested without incurring any of the costs traditionally associated with relativist views.

\section{Epistemic Relativism and Its Benefits}

Relativist views are those which hold that some particular set of truths or values are relative to (or are dependent on, or vary with) some standard (or set of standards), such as individual taste or cultural norms. The epistemic form of relativism that we are concerned with holds that epistemic justification is relative to some kind of epistemic framework, where an epistemic framework is a set of propositions that a given epistemic community uses to distinguish "good" beliefs, or those that should be believed, from "bad" ones, or those that shouldn't be believed. Put simply: epistemic relativists (usually) believe that justification is relative to some sort of standard of use. This is in contrast to epistemic absolutist views, according to which standards of justification remain the same regardless of time, place, culture, and so on.

This relational aspect of relativism, which says that justification is relative to some variable (in this case an epistemic framework), is the first of two key components of epistemic relativism. ${ }^{1}$ The second component is the endorsement of symmetry - the idea that the different possible epistemic frameworks cannot be ranked (Kusch 2016, 35). On one interpretation of symmetry, this component follows from the first: if all justification is relative to an epistemic framework, including justification of propositions or judgements about those epistemic frameworks themselves, then there can be no neutral, framework-independent ranking of different frameworks (Kusch 2016, 35). I think this is the correct interpretation, as I explain in "Relativising Epistemic Advantage" (forthcoming). As, however, many criticisms of relativism focus on a different interpretation of symmetry, known as equality (Kusch 2016, 35) or equal validity (Boghossian 2006, 1-2), the present paper focuses on this second interpretation. On this interpretation, all standpoints are equally correct.

The problems with epistemic relativism have been debated at length (and are discussed later in the paper). I want, however, to spend some time

\footnotetext{
${ }^{1}$ This two-part definition comes from Baghramian and Carter 2015. Since I first drafted this paper I've switched to explaining relativism as composed of three componentsdependency, plurality, and non-neutral symmetry (see Ashton forthcoming; Ashton 2019; Ashton and McKenna 2018) - but I still think the two-part definition (where dependency and plurality are united as "the relational aspect") is useful for distinguishing responses to relativism.
} 
elucidating the benefits of the view. I think there are two main benefits to epistemic relativism: first, that it can help us to resolve a deep-seated tension in our understanding of our own epistemic position and, second, that it can help to cultivate an important intellectual virtue.

The tension that I think epistemic relativism can help to resolve is between two conflicting intuitions that I think many of us have. One is that our resources for evaluating epistemic claims are in some sense limited. This intuition is revealed by the persistence of sceptical arguments, which often rely on the idea that the evidence available to us (such as perceptual and proprioceptive experiences) underdetermines the beliefs that we use it to support (such as those about one's having hands).

Despite this idea being very difficult to argue against, few of us accept, or even entertain, the sceptical conclusion that our beliefs are unjustified. We thus also have the (conflicting) intuition that our beliefs amount to knowledge and so are not too drastically compromised by our limited epistemic resources. This tension is at the heart of traditional epistemology, and so if epistemic relativism can resolve it, this will be a significant benefit.

Wittgenstein's work in On Certainty (1969) goes some way to helping us to understand this tension and is at the centre of the stratified relativism that I develop later in the paper. We can read Wittgenstein as offering something like the following argument. ${ }^{2}$

1. Rational support for a particular proposition must inspire a greater degree of confidence than the proposition itself.

2. By definition, there are no propositions that inspire a greater degree of confidence than our most certain beliefs.

Therefore,

3. There are no propositions that could rationally support our most certain beliefs.

The certainty with which we regard our most certain beliefs is thus the very same thing that makes us worry about them, and the tension we feel when considering scepticism is a product of these two seemingly incongruous facts.

By showing that justification for a belief lies in being relative to the certain-seeming propositions that make up our epistemic frameworks, epistemic relativism will explain the intuition that our epistemic standpoint is in some sense inadequate. Moreover, as we will see in section 5,

\footnotetext{
${ }^{2}$ For explanations of how such an argument can be extracted from Wittgenstein's fragmentary writings, see Pritchard 2016, chap. 4, and Ashton 2015, 5-6.
} 
epistemic relativism will do this without conceding scepticism and so will resolve the tension that results from this intuition.

The important intellectual virtue that relativism can help us to cultivate is intellectual humility. Empirical data suggests that even the beliefs that we might take to be least controversial have been debated at different points throughout history. Without relativism these cases might be thought to warrant an attitude of intellectual superiority, because the passage of time seems to allow us to think that we have "moved on," "developed," or now "know better." With our improved epistemic standpoint—or so the thought goes-we now have justification where those in the past did not.

But there are also cases of what we might call faultless disagreement amongst contemporaries, and even amongst epistemic peers, where there is no obvious asymmetry between the two disputants. ${ }^{3}$ In these cases superiority is harder to justify and starts to seem like intellectual arrogance. ${ }^{4}$ Epistemic relativism supports a less arrogant response to both kinds of cases, because it involves recognising that there are multiple sets of propositions that can be justified. Instead of promoting the development of intellectual arrogance, it promotes intellectual humility. ${ }^{5}$

It's important, however, that the type of relativism we endorse doesn't go too far the other way and fall into intellectual arrogance's opposing vices of obsequiousness, or servility (Tanesini 2016, 89). We will see in the final section that stratified epistemic relativism avoids this trap. It will allow for a plurality of definitions of justification that will enable us to explain these disagreements in a way that promotes intellectual humility and guards against both of its vices.

\section{Categorising Objections and Replies}

Untangling the various objections that epistemologists have directed at epistemic relativism is essential to rethinking the view. I discuss four in total. Before I do, it will be useful to explain the general formula that these objections take and to categorise the various general response types that are available.

Each objection points to some (allegedly essential) property of justification that would be lost on a relativist view and to reasons on the basis of this that relativism is untenable. The properties are: consistency, noncircularity, rational acceptability, and enabling criticism. The objections

\footnotetext{
${ }^{3}$ Faultless disagreement is well established as a motivator for semantic relativism (Kölbel 2004 and 2016; MacFarlane 2007 and 2014; Wright 2012; see also Hales 1997; Kinzel and Kusch 2018), and peer disagreement has been used to support epistemic relativism (Hazlett 2014; Kusch 2018).

${ }_{5}^{4}$ For a detailed - and eye-opening — account of intellectual arrogance, see Tanesini 2016.

${ }^{5}$ For more on intellectual humility, see Roberts and Wood 2003; Hazlett 2012; Christen, Alfano, and Robinson 2014; and Whitcomb et al. 2017.
} 
fall into two groups based on which component of the view is thought to jeopardise the property in question. The first three properties are thought to be lost due to the relational aspect of the view, and so they fall into the first group of objections. The last properties are said to be vulnerable because of symmetry, and so are in the second group of objections.

Regardless of which of these groups an objection falls into, there are four possible ways the relativist could react. The first is simply to deny that the property is lost on a relativist view. If the property is securable without any changes to the relativist view in question, then the objection fails.

The remaining responses all concede that the argument for the loss of the relevant property succeeds. Accordingly, I'll call these responses concessive. The concessive responses are outlined in table 1 .

The first of our three concessive responses is a timorous response. Timorous responses uncritically accept that the property in question is desirable and then either give up the view altogether or alter it so that the property highlighted by the objection can be regained (but at the expense of losing the relativist aspect of the view).

The other concessive responses are more critical. They begin by considering whether the property in question is really as desirable as the objection suggests. Someone who reaches the conclusion that the property in question is desirable will likely take a cautious strategy; she will identify exactly why the property is desirable - that is, what benefits it accruesand then explore whether those desirable benefits can be procured on a relativist view. There are two possible outcomes of this deliberation. Either it turns out that it isn't possible to secure the benefits of the property on a relativist view - this discovery warrants what I'll call a cautious anti-relativism - or it turns out that those benefits can be secured on a relativist view - in which case a cautious relativism is warranted.

Finally, a temerarious strategy is taken by someone who concludes that the property isn't desirable after all. This is the most revisionary of the four strategies, and it allows her to bite the bullet and maintain her relativist view in spite of the objection.

My aim in this paper is to lay the groundwork for the development of a cautious relativism, shaped by the concerns of some of the most prominent anti-relativist arguments. This tactic is concessive, because it doesn't

TABLE 1. Concessive responses to objections to relativism

\begin{tabular}{|c|c|c|c|}
\hline \multirow{3}{*}{$\begin{array}{l}\text { Uncritical } \\
\text { Alter/abandon the } \\
\text { view (timorous } \\
\text { anti-relativism) }\end{array}$} & \multicolumn{3}{|c|}{ Critical—is the property desirable? } \\
\hline & \multicolumn{2}{|c|}{ Property is desirable (cautious) } & Property isn’t \\
\hline & $\begin{array}{c}\text { View can't secure } \\
\text { benefits (cau- } \\
\text { tious anti-rel. })\end{array}$ & $\begin{array}{l}\text { View can secure } \\
\text { benefits }(\text { cau- } \\
\text { tious relativism })\end{array}$ & $\begin{array}{l}\text { desirable } \\
\text { (temerarious } \\
\text { relativism) }\end{array}$ \\
\hline
\end{tabular}


outright deny that the properties highlighted by each of the objections are lost on relativist views. And it is critical because I instead try to identify what is desirable about each of these properties before thinking about how to secure them. I then treat my findings as a set of constraints on a plausible epistemic relativism. I note these constraints throughout the next two sections. Then, in section 6, I show how a stratified relativism can meet all of them. I begin with the objections that find fault with the relational aspect of epistemic relativism.

\section{Objections to the Relational Aspect}

There are three main objections to the relational aspect of epistemic relativism. The first focuses on the property of consistency and often elicits a timorous strategy in response. I will deny that this objection applies to epistemic relativism. I'll then discuss two more objections, which focus on non-circularity and rational acceptability, respectively.

\subsection{Consistency}

The worry about the consistency — or rather the inconsistency_of justification relating to epistemic frameworks is rarely made explicit; most authors only discuss consistency objections in relation to truth relativism (see, e.g., Hales [1997], Boghossian [2006], and Kölbel [2016]). Despite this, it's still the first objection (in my experience) that comes to people's minds. And I think it incorporates a second worry that is more pressing.

I'll use Paul Boghossian's (2006) formulation of the consistency objection, as Boghossian is unusual in explicitly formulating it with epistemic, rather than alethic, relativism in mind. Although this formulation isn't especially sophisticated-Boghossian himself rejects it immediately-I think it clearly articulates what we are worried about losing when discussing this argument, and so it will be useful in compiling our list of constraints on epistemic relativism. Boghossian calls the problem "the problem of traditional refutation":

The claim "Nothing is objectively justified, but only justified relative to this or that epistemic system [or framework]" must be nonsense, for it would itself have to be either objectively justified, or only justified relative to this or that particular epistemic system. But it can't be objectively justified, since in that case it would be false if true. And it can't be justified only relative to the relativist's epistemic system, since in that case it is just a report of what he finds it agreeable to say. If he also invites us to join him, we need not offer any reason for declining since he has offered us no reason to accept. (Boghossian 2006, 83)

The idea, then, is to offer the relativist two options. She can either say that a statement key to her view, "Nothing is objectively justified, but 
only justified relative to this or that epistemic [framework]," is objectively justified - in which case her view is inconsistent (its truth falsifies itself). Or she can say that this statement is justified relative to her own framework - and so unpersuasive.

So, there is a clear route available to the relativist to retain consistency. The real worry is whether it's possible to do this without losing the capacity for persuasion. Consistency and persuasiveness are the basic marks of a respectable view in analytic philosophy, so finding that these two features are in tension is a legitimate concern, and a timorous response might seem tempting. But, as Boghossian points out, there is a way for the relativist to retain persuasiveness as well as consistency. As long as she can allow that the statement of her view is justified relative to some framework that she and her interlocutor share, then the worry about persuasiveness disappears.

In order to retain both consistency and persuasiveness, and thus meet the minimal requirements for respectability, epistemic relativism must therefore allow that an epistemic relativist can share some framework with her anti-relativist interlocutors. This is the first constraint on a plausible epistemic relativism. As we'll see in section 5, stratified epistemic relativism respects this constraint.

\subsection{Non-circularity}

The second objection to the relational aspect regards the loss of noncircular justification. This objection is especially interesting because relativism is often suggested to be motivated by attempts to avoid circularity and to retain non-circular justification (see, e.g., Sankey 2010; Carter 2016, chap. 5; and Seidel 2014, chap. 3). Nevertheless, the worry about non-circularity is raised by Michael Williams (2007). He distinguishes his own relational view of justification, which he calls Wittgensteinian "contextualism," from relativism, on the grounds that relativism relies on circular justification, and his view does not. As we will see, it's not clear that his view does avoid circularity. Still, his explanation of the problem, and certain aspects of his response to it, will be useful.

Recall, again, that the epistemic relativism we're interested in says that all epistemic judgements are made from within a particular framework or set of propositions, and so these are the ultimate "source" of justification. The problem Williams flags arises when we consider what justifies these source propositions. If all epistemic judgements we make must be made within our epistemic framework, then presumably we judge the source propositions by that framework too. Thus the only justification we can get from epistemic frameworks is circular (Williams 2007, 107).

This objection shouldn't warrant a timorous response. Circularity isn't always problematic, and so we should be a little more critical before we reject relativism and instead begin by determining why Williams 
thinks non-circular justification is desirable. It seems that his reason is that non-circular justification gives us a way to revise our epistemic frameworks - his defence of contextualism is grounded in the claim that it allows us to question the propositions that make up these frameworks, while relativism does not (Williams 2007, 107). This makes sense. If a view renders our epistemic frameworks unrevisable, then it will have difficulty explaining epistemic progress (or even just epistemic differences across time).

A temerarious response would suggest maintaining the relativist view even if it can't allow for framework revision. Given the problems we've just seen with a view that does this, I will take the more cautious approach. As noted earlier, I'm going to defend a cautious relativism and so aim to show that it's possible to get framework revision even without non-circular justification. Although the overall result will be quite different from the view Williams holds - he defends a cautious anti-relativism - many of the details are similar, and so it will make sense to begin with them.

In short, Williams's view is that epistemic frameworks don't need to rely on circular justification, because their source propositions can have "default entitlement." The idea, which is heavily influenced by the Wittgensteinian view discussed above, is that these source propositions are more certain for us than any other proposition, and so although they cannot be rationally supported (because there is nothing in which such support could be grounded), they also can't be doubted.

Source propositions play a special role in our justificatory practiceseverything else turns on them like a door turns on its hinges - and so although they are not the source of justification in the traditional sense, they do limit it in a way that makes them a legitimate basis for further beliefs. Crucially, Williams maintains that on this view these propositions (which are sometimes called "hinge propositions," can "acquire a measure of indirect validation [and] can be questioned and revised" [2007, 103]). In other words, he thinks they can secure framework revision despite this apparent lack of support.

I agree that it's possible to secure framework revision on a view like this but don't think we can reasonably describe this view as anything other than relativist. This is because it can be shown to involve circular justification after all. We can make both of these points clear with an example: Ana is an epistemic agent operating within framework $\mathrm{A}$, which has various source propositions ( $A_{1}, A_{2}$, and so on). In order for this system to be revised, someone operating within it must be capable of questioning some of these source propositions. Ana is competent in all of the required ways, and so is capable of revising system A.

Now, in which framework do the questions that prompt these revisions originate? Presumably, it needs to be a framework that Ana operates within, so that she can act on the questions, but not framework A itself, as this is constituted by the very propositions in question. It looks as though 
we need to allow that agents can access multiple frameworks. Perhaps Ana can also access some other framework, B, and use what she learns there to revise framework A. At first glance this seems to break the circle: framework A now has some justification from outside itself, and so the problem of circularity has been avoided. But if we look more closely, this just opens the view to accusations of a deeper level of circularity. Framework B is also constituted by a number of source propositions that are default entitled, and these too will need to be eligible for revision.

We can now ask the same question again: In which framework do the questions that prompt these revisions arise? Our options are that they arise in some third framework, and that this is revised on the basis of questions from a fourth framework, and so on, infinitely; or at some point we must say that a framework justifies itself; or else, we must say that one of the frameworks in the chain gets some justification from one of the frameworks to which it also lends justification. This trilemma should be familiar: it is the Agrippan trilemma that we're faced with when justifying individual propositions but scaled up to justification of epistemic frameworks. I take it that the infinitist and self-justification options are as unappealing on this larger scale as they are on the scale of individual propositions, and so anyone who is tempted by the idea of relational justification (whether it is a relativist or a contextualist version) will again be pushed into accepting the circular option. The contextualist view that Williams describes thus doesn't secure non-circularity after all (and, by his definition, turns out to be relativist after all).

Cautious anti-relativism hasn't been successful, then, but I think that a cautious relativism is still achievable and can draw from the picture of justification that Williams describes. There are two important features of this picture that we can take as constraints on a plausible epistemic relativism: the first is that there are multiple epistemic frameworks accessible by a single subject (as we saw with subject A), and the second is that justification can move between frameworks in both directions. This allows subject A to "step" between, say, framework A and framework B, and in each case to draw on propositions from the other framework to inform her understanding of her current one. This would work as follows: The propositions of framework A (A1, A2, and so on) are most certain, and so cannot be revised, within the context of framework A. Within the context of framework B, however, a different set of propositions (B1, B2, and so on) are most certain. A subject who has access to both frameworks therefore has additional resources to deploy and is able to revise both sets of frameworks. The propositions of framework A can be revised in accordance with the propositions of framework B, and vice versa.

It's important to make clear that this kind of framework revision is rational. If we avoided non-circularity only by showing that frameworks were ultimately non-rational, then relativism would not look much more appealing. And someone could easily be misled into thinking that this kind 
of revision was not rational. I say that rational revision is a two-way process: not only can framework A be revised based on framework B propositions, framework B can be revised based on the propositions of framework A, too. The Wittgensteinian view of justification that my view is based on requires the propositions that inspire revisions (that is, those that play the role of supporting or doubting a proposition) to be more certain than the propositions to be revised. This means both that the propositions of framework A must be more certain than the propositions of framework B, and the propositions of framework B must be more certain than the propositions of framework $\mathrm{A}$, and this sounds like a contradiction.

Assuming that there are no true contradictions, this can't be what is going on in the process that I describe. One possibility, and the one that leads to the worries about non-rational revision, is that only one direction of revisions can be rational. Perhaps the propositions of framework A are more certain than those of framework B, and so framework B can be rationally revised, but any revision of framework A will be non-rational. If this were the only possibility, then this would be a problem for my view. There is, however, another possibility that allows rational revision to take place.

The other possibility, the one that I endorse, is that the propositions of framework A are more certain than the propositions of framework B relative to framework $A$. Likewise, the propositions of framework B are more certain than the propositions of framework A, relative to framework $B$. There is no contradiction here. Revision can happen in either direction, depending on which framework is relevant at the time.

\subsection{Rational Acceptability}

The third worry about the relational aspect of relativism also comes from Boghossian (2006). This is a worry about whether epistemic frameworks can be endorsed, and whether the beliefs that they support can be rationally accepted.

Boghossian starts by telling us that-according to his understanding of relativism-particular unrelativised epistemic judgements, such as the following, are false:

1. Copernicanism is justified by Galileo's Observations. $(2006,84)$

This is because they make reference to objective justification, and according to the relativist only relative justification is possible. Instead, Boghossian suggests the relativist would recommend we use modified, relativised versions of these particular judgements, such as:

2. Copernicanism is justified by Galileo's obeservations relative to a system, Science, that I, the speaker, accept. $(2006,85)$ 
Boghossian then points out that a similar argumentative move can be made about basic epistemic principles like Observation:

(Observation): For any observational proposition $\mathrm{p}$, if it visually seems to $\mathrm{S}$ that $\mathrm{p}$ and circumstantial conditions $\mathrm{D}$ obtain, then $\mathrm{S}$ is prima facie justified in believing p. $(2006,85)$

Just as the particular unrelativised judgement in (1) was (according to Boghossian's relativist) false, because it made reference to relative justification, the general unrelativised principle in (2) also is false.

The crux of the worry is that in order to count as having reasons for our beliefs we need to endorse the principles those beliefs rely on, but it's not clear that we can endorse principles we know to be false. So, if the relativist is right about the impossibility of objective justification, we have to give up the endorsement of basic epistemic principles and the rational acceptance of our beliefs.

One option at this point would be to disagree with Boghossian's characterisation of the relativist position as viewing judgements like (1) as false. Kusch (2009) does this, taking the non-concessive route of arguing that the relativist would instead view such "Judgements" as incomplete, and so denying that rational acceptability is lost on a relativist view. ${ }^{6}$

But what if we concede Boghossian's claim that relativism loses rational acceptability - what are our options then? In order to see how we should respond to this worry (that is, either timorously or with caution) we need to understand what the benefits of rationally acceptable justification are. According to Boghossian $(2006,86)$, if relativists don't accept the propositions of their own frameworks, then we can't make sense of them having reasons (even relative reasons) for believing the non-framework propositions that they do. Rational acceptability is important because it provides a coherent basis for our beliefs.

At this point it will be useful to distinguish two different sorts of basis that our beliefs can have. One sort of basis is made up of explicit and often articulable reasons - the kind of thing we have in mind when we imagine someone consciously considering a judgement like whom to vote for in a general election. Perhaps some people accept principles like Observation on this sort of basis, but I suspect most don't. What I think is much more common is accepting Observation on an implicit, unarticulated basis-in the same way that we (ordinarily) accept that the floor beneath us will hold our weight without ever thinking about it.

This second, implicit basis is what we discussed earlier under the name "default entitlement" (see Wright 2004). Put most basically, the idea is that

\footnotetext{
${ }^{6}$ Wright 2008 makes a different criticism, arguing that judgements like (1) are true — but relatively so - though this requires a defence of alethic relativism rather than epistemic.
} 
we don't need rational support in order to accept the principles, judgements, or propositions that play an indispensable role in our epistemic lives. If not accepting these principles would result "not in an increase in rigour or solidity but merely in cognitive paralysis," then we are entitled to accept them (Wright 2004).

One worry about this proposal is that it might seem to suggest that the reasons we have for endorsing our epistemic frameworks are "merely" practical, or pragmatic, rather than "truly epistemic." There are good reasons to question this sort of hierarchy (see Wright 2014), but I don't think we need to. Instead, we can embrace a constitutivist view of epistemic rationality. According to such a view, rationality is constituted by our basic framework propositions and principles. Wittgenstein (1969) points toward such a view himself:

342. That is to say, it belongs to the logic of our scientific investigations that certain things are in deed not doubted.

343. But it isn't that the situation is like this: We just can't investigate everything, and for that reason we are forced to rest content with assumption. If I want the door to turn, the hinges must stay put.

What Wittgenstein is trying to make clear is that we don't just refrain from questioning our framework propositions because it is difficult or inconvenient to question them, but rather because to do so would mean abandoning our rational epistemic practices altogether. The fact that "certain things are in deed not doubted" is a component part of epistemic rationality.

Annalisa Coliva (2015) has developed this idea substantially and points out that if rationality is (or species of rationalities are) constituted by these unquestionable framework propositions, then the idea that they don't provide an adequate basis for rational acceptability is utterly confused. ${ }^{7}$ These commitments are the very fabric of rationality - the thing against which rational acceptability is measured - and so the question of whether or not they are rationally acceptable is a category mistake.

This constitutivist approach allows us to secure (epistemic) reasons for belief very easily. Even if someone has never consciously considered the truth of basic principles like Observation, if he operates with an epistemic framework partly composed of them he can be said to "accept" them in

\footnotetext{
${ }^{7}$ Coliva is careful to argue that her view allows for only one set of propositions that constitute rationality for human agents. (She achieves this by focusing only on propositions that relate to our "basic" epistemic practices, those that "[do not] presuppose other instances of [themselves] and [are] necessary for other epistemic practices" [2015, 141]). On the view I will eventually defend, there are multiple sets of propositions that can count as "rational" for an agent (and it might even make more sense to think of there being multiple kinds of rationality).
} 
virtue of acting in accordance with them. Whenever an agent believes a proposition that visually seems to her to be the case (when circumstances D obtain), or she judges such a proposition to be justified, then we can say that she accepts Observation.

As long as we accept a constitutivist understanding of rationality (or rationalities), then either rational acceptability or the benefits of reasons for belief are possible to secure an epistemic relativist view and will remain in the running for offering a plausible understanding of justification. As we will see in section 5, a stratified epistemic relativism can meet this constraint.

\section{Objections to Equal Validity}

As I said in section 2, I don't think that equal validity is a necessary-or even coherent - component of relativism. I prefer to characterise the symmetry component of epistemic relativism as non-neutrality rather than equal validity. But in the interest of formulating a cautious relativism in response to the most common characterisation of epistemic relativism, I'll now consider an objection to equal validity. ${ }^{8}$ This criticism focuses on enabling criticism, and my response to it will give us the last constraint we need in order to construct a plausible epistemic relativism.

\subsection{Enabling Criticism}

Although Boghossian's argument against equal validity is unconvincing in light of the discussion so far, I will concede that a related problem does appear pressing. The problem is that on a picture where all epistemic frameworks are equally valid we are unable to criticise people operating within frameworks different to our own.

For example, say someone claims to know some fact that we believe to be unjustifiable (for example, that astrology is a reliable way to predict personality traits). We want to criticise her, and we want to be able to say that her belief is unjustified, but if she is operating within some epistemic framework in which it is justified, then we are unable to do this.

It's easiest to see why we value this kind of criticism when we consider beliefs that have moral implications. If someone claims, contrary to our moral beliefs, that a particular person is in some way less valuable due to her race or gender, then we want to criticise the claimer; this is partly

\footnotetext{
${ }^{8}$ And I think that a parallel worry can probably be raised against epistemic relativism characterised in terms of non-neutrality, so it will be worth thinking about.
} 
because we feel strongly that her belief is unjustified tout court, and partly because we hope to be able to persuade her to change her mind. ${ }^{9}$

The loss of this second benefit appears to be the thought behind the anti-relativist views put forward by Duncan Pritchard and Annalisa Coliva. Pritchard (2011) and Coliva (2015) both note that accepting relativism requires us to accept the possibility of there being two epistemic frameworks (or sets of practices), which give rise to different, and conflicting, conclusions about what is justified (or epistemically rational). For Pritchard this idea is expressed by the incommensurability thesis: "It is possible for two agents to have opposing beliefs which are rationally justified to an equal extent where there is no rational basis by which either agent could properly persuade the other to revise their view" $(2011,269)$. Coliva expresses it thus: "[T]here could be - either in fact or in principleother practices, which would determine different notions of epistemic rationality, with their distinctive presuppositions, which would be mandated by the very lights of these alternative notions" (2015, chap. 4 , $\S 4$ ).

In both cases the idea is that the epistemic relativist's insistence that different frameworks are equally valid means that there is nothing that can be said from within either framework that would persuade an interlocutor from the rival framework to change her mind.

I think the response to this objection should be two-pronged. First, as with the final objection to the relational aspect of relativism, we shouldn't overstate how often we can expect this scenario to arise. Although we might often find ourselves in disagreement with others about epistemic matters, we have no reason to think that all or even many of these disagreements would arise due to using different epistemic frameworks. Instead, some of them might be between people using the same framework, and one (or both) of them has just made an error somewhere along their chain of reasoning. In these cases their criticism still, in principle, has the power to persuade.

Coliva claims that on her view this will always be the case, as the propositions that she treats as framework propositions are supposedly so basic that we can't conceive of creatures that could lack them (2015, chap. 4, $\S 4)$. She essentially denies the possibility of frameworks other than our own (on the basis that they are inconceivable), and so her strategy can be categorised as a cautious anti-relativism.

\footnotetext{
${ }^{9}$ The objection about enabling criticism is different from the non-circularity objection in 4.2, above, because (a) it isn't about criticising the underlying epistemic framework but instead is about the non-framework propositions that the framework justifies, and (b) this criticism is valuable not because it allows us to revise our own epistemic frameworks but because we want to be able to persuade our interlocutors to revise theirs.

This objection is similar, however, to a problem that Boghossian explores in relation to moral relativism - he worries that the kinds of criticism moral relativism can offer us is no more than trivial claims about what our epistemic frameworks entail, rather than interesting claims about morality itself $(2006,50)$.
} 
Pritchard makes a similar point, also defending a cautious antirelativism. He claims that even in those cases where the two subjects seem to hold completely opposing views, persuasion can happen as long as both the subjects are sincerely attempting to seek the truth. In those cases where one or both parties are instead holding their belief dogmatically (perhaps for religious reasons) the debate will be intractable, but for reasons that are practical, rather than epistemic (Pritchard 2011, 20-21).

I think the general strategy that Coliva and Pritchard share-to limit the number of cases of genuinely intractable disagreement - is right, but Coliva's strategy won't completely carry across to the view that I want to defend, because it doesn't allow for there to be multiple epistemic frameworks. Instead the epistemic relativist can paint a picture of justification on which there is overlap between different epistemic frameworks. By overlap I mean that there are agents who can access two or more frameworks at once and thus enable criticisms and possibly revision. This will mean that in most cases of disagreement, even between subjects operating within different epistemic frameworks, there will be at least one set of shared commitments that the subjects can use to criticise each other's systems. There is thus potential for persuasion to take place.

Once we do this, I think a temerarious response might start to look appealing. If there are only a few cases where people are using epistemic frameworks completely different to ours, and we concede that relative to their own framework they are justified, then criticism starts to look a little petty or unduly arrogant, and a dose of intellectual humility might be exactly what we need. I have said, however, that I will not defend any temerarious responses in this paper. Instead, I will now develop a version of epistemic relativism that meets all of the constraints I have listed and thus avoids the key objections that have been levelled against previous versions.

\section{Stratified Epistemic Relativism}

Discussing the objections above has resulted in five constraints, which we can use to sketch out the shape of a cautious epistemic relativism. The goal is to formulate a version that secures the benefits of relativism that I introduced earlier, without succumbing to any of the objections discussed. For ease of reference, I'll begin by summarising the five constraints.

In order to ensure that her view is both persuasive and consistent:

(i) The cautious epistemic relativist must be able to share some framework with his critics.

In order to ensure that epistemic frameworks provide justification that can evolve over time (and thus are able to explain epistemic progress): 
ii. Subjects must be able to access multiple epistemic frameworks. And:

iii. Justification must move between frameworks in both directions.

In order to ensure that the justification provided by epistemic frameworks is rationally acceptable:

iv. The cautious epistemic relativist must understand rationality constitutively.

Finally, in order to enable criticism and allow for the potential for persuasion:

v. There must be multiple areas of overlap between different epistemic frameworks.

I will now sketch out a view that I think respects all of these constraints. I'll call this view stratified epistemic relativism, because it emphasises the multiple layers, or strata, of frameworks that each epistemic agent has available to her. On this picture, an individual agent's justificatory resources are a cross-section of four different strata of frameworks:

Pursuit Frameworks: The sets of propositions used and developed in the various epistemic, or scientific, inquiries and interests that an agent adopts, such as the study of history or philosophy. (Cf. Michael Williams's methodological contexts [1991; 2007] and Robin McKenna's interests contextualism [2011].)

Community Frameworks: The sets of propositions used to play, and developed whilst playing, different roles within various communities, such as the role of a doctor or that of a parent. (Cf. Sarah Wright's virtue contextualism [2010].)

IDENTITY FRAMEWORKs: The sets of propositions used to navigate, and developed whilst navigating, the various forms of privilege one enjoys and oppression one faces, such privilege and oppression relating to race, gender, class, and ability. (Cf. the standpoint theories defended by Patricia Hill Collins [1986], Nancy Hartsock [1983], Alison Wylie [2003], and others.)

RATIONAL FRAMEWORK: The broad framework that we all share in virtue of being epistemic agents. (Cf. Annalisa Coliva's constitutivist rationality [2015].)

My intention isn't to defend this view. I only want to sketch out a possible version of cautious relativism, and so I won't offer more detailed accounts of each of these frameworks here. I will, however, highlight four important points about the picture I've just sketched. 
First, as the examples above should make clear, agents will typically have access to multiple frameworks within each of the first three strata. For example, one single person could have access to the pursuit framework(s) relevant to a scientist, the community framework(s) relevant to a parent, and the identity framework(s) relevant to an economically privileged black woman.

Secondly, the frameworks in the first stratum are, generally speaking, the narrowest, while frameworks in further strata are increasingly broad, up to the single rational framework that is the broadest and encompasses all epistemic agents.

Thirdly, we should be careful to avoid overemphasising the significance of this ordering. No single framework or strata of frameworks should be considered the ultimate "source" of justification, and any framework can be revised on the basis of questions raised in any other framework (as long as there is some agent who relies on both frameworks in order to carry out the revisions). In other words, we should not think of these different layers in a hierarchical way - with any of the strata being more "fundamental" or more closely allied to "genuine" or "objective" justification.

Rather, we should recognise that justification can move in both directions between frameworks, regardless of what stratum they occupy. For example, this process could happen between frameworks within the same stratum, such as two community frameworks (for example, parent and local councillor), and between frameworks in contiguous strata, such as a community framework and an identity framework (for example, parent and woman), and between frameworks from non-contiguous strata, such as a pursuit framework and the rational one (for example, historian and rational agent).

Finally, this picture of justification is complex. I consider this to be a virtue of the view, as it means that it reflects the rich and multi-faceted justificatory practices that we actually have. More important for our present purposes, the fact that on stratified relativism agents can access multiple frameworks of different scopes across different strata also allows us to respect the six constraints I drew out in sections 3 and 4. I will demonstrate this now.

As we have seen, stratified relativism allows that epistemic agents can access multiple epistemic frameworks. This means that it respects constraint (ii). This feature also makes clear that the relativist and her critics will share some epistemic framework - at the very least they will share the broad rational framework that all epistemic agents rely on, but chances are they will share plenty of frameworks in other strata too. What is most relevant to the relativism debate is that they will presumably each share a pursuit framework required for philosophy. Thus the view also meets constraint (i).

As I've already said, this picture allows for the possibility of justification moving in both directions between the different epistemic frameworks. This shows that it respects constraint (iii). Furthermore, the broad rational framework ensures that the view meets constraint (v), because it 
amounts to constitutive rationality. Finally, there is clearly a significant amount of overlap between different frameworks - where overlap means that different frameworks are occupied by the same agents(s) - and this should be sufficient both to enable criticism of other frameworks and to allow for the potential for these frameworks to be revised accordingly. Constraint (vi) is also respected then. Stratified epistemic relativism thus meets all the requirements for a plausible epistemic relativism.

\section{Conclusion}

In closing, I will make explicit how endorsing stratified relativism secures the benefits mentioned in section 1. Recall that I highlighted two benefits: one was the ability to resolve the tension between two conflicting intuitions about our own epistemic position, and the other was to enable us to develop the intellectual virtue of humility.

Stratified relativism secures the first benefit by staying loyal to the Wittgensteinian picture of justification that I described. It says that all justification is relative to a cross-section of different epistemic frameworks, and in doing so it acknowledges the intuition that our epistemic position is in some sense limited. At the same time, it highlights the fact that these frameworks are made up of those propositions that are most certain for a particular agent (in virtue of her pursuits, her community, her identity, and her status as an epistemic agent). This means that there is a very important sense in which the beliefs resulting from this epistemic position are perfectly adequate, and so the view also makes room for the intuition that our beliefs amount to knowledge in spite of our limited epistemic resources.

To see this, consider what you would think if someone were to tell you that she was absolutely certain of some proposition, but that she didn't believe a proposition that was entailed by it. If anything seems epistemically inappropriate, I'd venture, this does. In accounting for both of these intuitions stratified relativism resolves the deep-seated tension between them, and it secures the first benefit of epistemic relativism.

The second benefit of epistemic relativism is also secured by stratified relativism. By revealing justification to be a function of the different epistemic frameworks that we each inhabit, it eliminates the notion of "objective" justification. This removes the temptation for intellectual arrogance that can occur when the possibility of one's own epistemic position being closer to or further from the ideal one is on the table. If there is no objective justification, then there is no (single) ideal set of justificatory propositions; instead there are multiple, equally valid, sets.

Importantly, this realisation shouldn't send us too far towards the opposing intellectual vice, either. This is because when the stratified relativist acknowledges the lack of objective justification she also specifies that there is no hierarchy to the remaining relativized notions of justification. This allows her to increase the importance of other epistemic 
viewpoints without devaluing her own. Stratified relativism thus avoids both intellectual arrogance and intellectual servility and obsequiousness, instead striking the golden mean of intellectual humility, and so secures the second benefit of epistemic relativism.

Stratified relativism is a view on which it is possible to secure the appealing, beneficial features of relativism about epistemic justification, without having to accept any problematic consequences.

Division of Law and Philosophy

University of Stirling

Stirling, FK9 4LA

United Kingdom

nataliealanaashton@gmail.com

\section{Acknowledgments}

Research on this paper was assisted by funding from the ERC Advanced Grant Project "The Emergence of Relativism" (Grant No. 339382).

\section{References}

Ashton, Natalie Alana. 2015. "Undercutting Underdetermination-Based Scepticism." Theoria 81, no. 4:333-54. At https://doi.org/10.1111/ theo.12076.

- 2019. "The Case for a Feminist Hinge Epistemology." WittgensteinStudien 10, no. 1:153-63. At https://doi.org/10.1515/witt-2019-0009.

- Forthcoming. "Relativising Epistemic Advantage." In Routledge Handbook of Philosophy of Relativism, edited by Martin Kusch. New York: Routledge.

Ashton, Natalie Alana, and Robin McKenna. 2018. "Situating Feminist Epistemology." Episteme (10 April): 1-20. At https://doi.org/10.1017/ epi.2018.11.

Baghramian, Maria, and J. Adam Carter. 2015. "Relativism." In Stanford Encyclopedia of Philosophy (Fall 2015 Edition), edited by Edward N. Zalta. At https://plato.stanford.edu/archives/win2018/entries/relativism/.

Boghossian, Paul. 2006. Fear of Knowledge. Oxford: Oxford University Press. At https://doi.org/10.1093/acprof:oso/9780199287185.001.0001.

Carter, J. Adam. 2016. Metaepistemology and Relativism. Basingstoke: Palgrave Macmillan.

Christen, Markus, Mark Alfano, and Brian Robinson. 2014. "The Semantic Space of Intellectual Humility." In Proceedings of the European Conference on Social Intelligence, edited by Andreas Herzig and Emiliano Lorini, 40-49. Toulouse: IRIT-CNRS, Toulouse University.

Coliva, Annalisa. 2015. Extended Rationality: A Hinge Epistemology. Basingstoke: Palgrave Macmillan. 
Collins, Patricia Hill. 1986. "Learning from the Outsider Within: The Sociological Significance of Black Feminist Thought." Social Problems 33, no. 6 (1 December): s14-32. At https://doi.org/10.2307/800672.

Hales, Steven D. 1997. "A Consistent Relativism.” Mind 106, no. 421:33-52. Hartsock, Nancy C. M. 1983. "The Feminist Standpoint: Developing the Ground for a Specifically Feminist Historical Materialism." In Discovering Reality, edited by Sandra Harding and Merrill B. Hintikka, 283-310. Synthese Library 161. Dordrecht: Reidel. At https://doi.org/ 10.1007/0-306-48017-4_15.

Hazlett, Allan. 2012. "Higher-Order Epistemic Attitudes and Intellectual Humility." Episteme 9, no. 3 (September): 205-23. At https://doi.org/ 10.1017/epi.2012.11.

-. 2014. "Entitlement and Mutually Recognized Reasonable Disagreement." Episteme 11, no. 1 (March): 1-25. At https://doi.org/ 10.1017/epi.2013.46.

Kinzel, Katherina, and Martin Kusch. 2018. "De-Idealizing Disagreement, Rethinking Relativism." International Journal of Philosophical Studies 26, no. 1 (1 January): 40-71. At https://doi.org/10.1080/09672559.2017. 1411011 .

Kölbel,Max. 2004. "Faultless Disagreement." Proceedingsof the Aristotelian Society 104, no. 1:53-73. At https://doi.org/10.1111/j.0066-7373.2004. 00081.x.

- 2016. “Aesthetic Judge-Dependence and Expertise.” Inquiry 59, no. 6 (17 August): 589-617. At https://doi.org/10.1080/0020174X.2016.1208917. Kusch, Martin. 2009. "Epistemic Replacement Relativism Defended." In EPSA Epistemology and Methodology of Science, edited by M. Suárez, Mauro Dorato, and M. Rédei, 165-75. Dordrecht: Springer.

- 2016. "Wittgenstein's On Certainty and Relativism." In Analytic and Continental Philosophy Methods and Perspectives, Proceedings of the 37th International Wittgenstein Symposium. Berlin: De Gruyter. At https://doi.org/10.1515/9783110450651-003.

— 2018. "Disagreement, Certainties, Relativism." Topoi (22 June): 1-9. At https://doi.org/10.1007/s11245-018-9567-z.

MacFarlane, John. 2007. "Relativism and Disagreement." Philosophical Studies 132, no. 1:17-31. At https://doi.org/10.1007/s11098-006-9049-9.

- 2014. Assessment Sensitivity: Relative Truth and Its Applications. Oxford: Oxford University Press.

McKenna, Robin. 2011. "Interests Contextualism." Philosophia 39 (December): 741-50.

Pritchard, Duncan. 2011. "Wittgenstein on Scepticism." In The Oxford Handbook of Wittgenstein, edited by Marie McGinn and Oskari Kuusela, 563-75. Oxford: Oxford University Press.

- 2016. Epistemic Angst: Radical Skepticism and the Groundlessness of Our Believing. Soochow University Lectures in Philosophy. Princeton: Princeton University Press. 
Roberts, Robert C., and W. Jay Wood. 2003. Humility and Epistemic Goods. Oxford:Oxford UniversityPress. Athttps://www.oxfordscholarship.com/ view/10.1093/acprof:oso/9780199252732.001.0001/acprof-9780199252 732-chapter-12.

Sankey, Howard. 2010. "Witchcraft, Relativism and the Problem of the Criterion." Erkenntnis 72, no. 1:1-16. At https://doi.org/10.1007/ s10670-009-9193-7.

Seidel, Markus. 2014. Epistemic Relativism: A Constructive Critique. London: Palgrave.

Tanesini, Alessandra. 2016. "I-'Calm Down, Dear': Intellectual Arrogance, Silencing and Ignorance." Aristotelian Society suppl. 90, no. 1 (1 June): 71-92. At https://doi.org/10.1093/arisup/akw011.

Whitcomb, Dennis, Heather Battaly, Jason Baehr, and Daniel HowardSnyder. 2017. "Intellectual Humility: Owning Our Limitations." Philosophy and Phenomenological Research 94, no. 3: 509-39. At https://doi.org/10.1111/phpr.12228.

Williams, Michael. 1991. Unnatural Doubts: Epistemological Realism and the Basis of Scepticism. Princeton: Princeton University Press.

- 2007. "Why (Wittgensteinian) Contextualism Is Not Relativism." Episteme 4, no. 1 (February): 93-114. At https://doi.org/10.3366/ epi.2007.4.1.93.

Wittgenstein, Ludwig. 1969. On Certainty. Edited by G. E. M. Anscombe and G. H. von Wright. Translated from German by D. Paul and G. E. M. Anscombe. New York: Harper Torchbooks.

Wright, Crispin. 2004. "On Epistemic Entitlement: Warrant for Nothing and Foundations for Free?" Aristotelian Society suppl. 78, no. 1:167212. At https://doi.org/10.1111/j.0309-7013.2004.00121.x.

_. 2008. "Fear of Relativism?" Philosophical Studies 141, no. 3: 37990. At https://doi.org/10.1007/s11098-008-9280-7.

- 2012. Replies, Part III: Truth, Objectivity, Realism, and Relativism: Blackburn, Shapiro, and Rovane. Oxford: Oxford University Press. At https://www.oxfordscholarship.com/view/10.1093/acprof:oso/97801 99278053.001.0001/acprof-9780199278053-chapter-17.

- 2014. On Epistemic Entitlement, Volume 2: Welfare State Epistemology. Oxford: Oxford University Press. At https://www.oxfor dscholarship.com/view/10.1093/acprof:oso/9780199658343.001.0001/ acprof-9780199658343-chapter-11.

Wright, Sarah. 2010. "Virtues, Social Roles, and Contextualism." Metaphilosophy 41, nos. 1-2 (January): 95-114. At https://doi.org/ 10.1111/j.1467-9973.2009.01629.x.

Wylie, Alison. 2003. "Why Standpoint Matters." In Science and Other Cultures: Issues in Philosophies of Science and Technology, edited by Robert Figueroa and Sandra G. Harding, 26-48. New York: Routledge. 